\title{
PENYELIDIKAN LETAK AKUMULASI LINDI DAN ARAH REMBESAN DENGAN MENGGUNAKAN KONFIGURASI WENNER-SCHLUMBERGER DI TPAS AMPANG KUALO KOTA SOLOK
}

\author{
Yoszi Mingsi Anaperta ${ }^{1}$ \\ Fitra Rifwan ${ }^{2}$ \\ Adree Octova ${ }^{3}$
}

\begin{abstract}
TPAS Ampang Kualo is a final waste dumping area in Kota Solok of Sumatera Barat. The research at TPAS Ampang Kualo aims to know the distribution of leachate. Geolistrik resistivity method by Wenner - Schlumberger configuration is used for data retrieval Resistivity meter MAE X612 EM. The measurement data is then converted by using Res2dinv software to generate $2 D$ resistivity profile and Voxler 4.0 software for $3 D$ resistivity profile. The results show that leachate seepage at TPAS Ampang Kualo on track one was around a leachate pond stretching from South to North. The leachate was detected at depths between of 2.10 to 5.80 meters. In track two, the presence of leachate was indicated around a leachate pond stretching from east to west. It was detected at depths beetween of 1.50 to 6.35 meters. The trajectory three was taken around the residential population stretching from South to North that cuts out the flow of the leachate ditch. The leachate was detected at a depth of 0.25 to 7.38 meters. It was concluded that the distribution of TPAS Ampang Kualo leachate spread from the South to the Southwest was down in a small ditch flow for leachate disposal that ending at Green Hills Arya Residen.
\end{abstract}

Keywords: TPAS Ampang Kualo, Leachate, Geolistrik Resistivity Method, Wenner-Schlumberger Configuration

\section{INTISARI}

TPAS Ampang Kualo merupakan daerah pembuangan limbah akhir di Kota Solok, Sumatera Barat. Penelitian di TPAS Ampang Kualo bertujuan untuk mengetahui distribusi lindi. Pengambilan data menggunakan Resistivity meter MAE X612 EM dengan metode geolistrik tahanan jenis konfigurasi Wenner Schlumberger. Data pengukuran selanjutnya diinversi dengan menggunakan software Res2dinv untuk memunculkan profil resistivitas 2D dan software Voxler 4.0 untuk profil resistivitas 3D.. Hasilnya menunjukkan bahwa rembesan lindi di TPAS Ampang Kualo di jalur satu ada di sekitar kolam lindi yang membentang

\footnotetext{
${ }^{1}$ Fakultas Teknik Universitas Negeri Padang

2 Fakultas Teknik Universitas Negeri Padang

${ }^{3}$ Fakultas Teknik Universitas Negeri Padang
} 
VOL. 10 NO. 3. Oktober 2017

dari Selatan ke Utara. Lindi terdeteksi pada kedalaman antara 2,10 sampai 5,80 meter. Di jalur kedua, keterdapatan lindi diindikasikan di sekitar kolam lindi yang membentang dari Timur ke Barat. Hal tersebut terdeteksi pada kedalaman antara 1,50 sampai 6,35 meter. Lintasan tiga diambil di sekitar daerah perumahan yang membentang dari Selatan ke Utara yang memotong aliran selokan lindi. Lindi dideteksi pada kedalaman 0,25 sampai 7,38 meter. Disimpulkan bahwa distribusi lumpur TPAS Ampang Kualo yang menyebar dari Selatan ke Barat Daya sampai aliran parit kecil untuk pembuangan lindi yang berakhir di Green Hills Arya Residen

Kata Kunci: TPAS Ampang Kualo, Leachate, Metode Geolistrik Resistiviti, Konfigurasi Wenner-Schlumberger 


\section{PENDAHULUAN}

Tempat Pembuangan Akhir Sampah (TPAS) merupakan tempat dimana sampah diisolasi secara aman agar tidak menimbulkan gangguan terhadap lingkungan sekitarnya. Oleh karena itu diperlukan penyediaan fasilitas dan perlakuan yang benar agar keamanan tersebut dapat dicapai dengan baik. Salah satu dampak dari pengelolaan TPAS yang kurang baik adalah pencemaran terhadap air tanah. Umumnya TPAS di Indonesia masih memakai sistem open dumping dimana sampah ditumpuk menggunung tanpa ada lapisan geotekstil dan saluran lindi. Akibatnya adalah terjadinya pencemaran air tanah dan udara disekitar TPAS Tempat Pembuangan Akhir Sampah (TPAS) Ampang Kualo di Kota Solok Kelurahan Nan Balimo, Kota Solok. TPAS Ampang Kualo menerapkan sistem open dumping dengan luas lahan hanya 1,4 Ha dengan ketinggian maksimal tampung sampah 15 meter. Oleh karena itu diperlukan penyelidikan mengenai arah sebaran dan letak akumulasi lindi di sekitar TPAS Ampang Kualo. Keadaan TPAS Ampang Kualo dapat dilihat pada gambar 1.
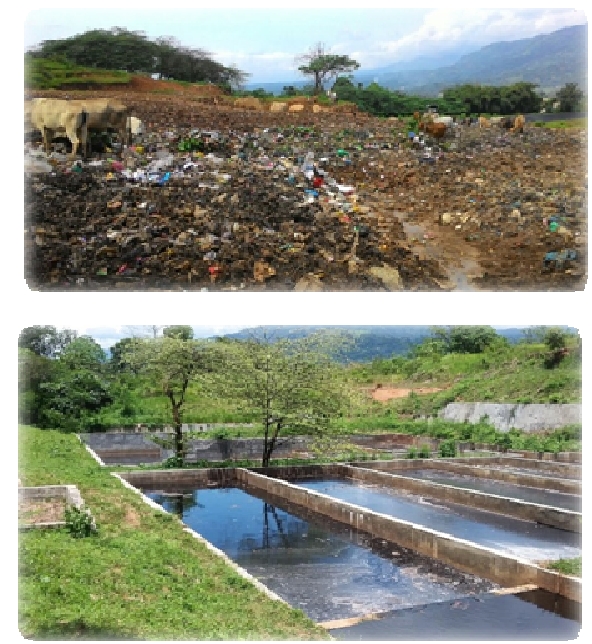

Gambar 1. Keadaan TPAS Ampang Kualo

\section{PENDEKATAN \\ MASALAH \\ Lokasi Daerah Penelitian}

Secara administrasi lokasi penelitian termasuk ke dalam wilayah Kelurahan Nan Balimo Kota Solok, Provinsi Sumatera Barat, Indonesia. TPAS Ampang Kualo dapat ditempuh dari Kota Padang kurang lebih selama 2 jam melewati jalan darat. Secara geografis Ampang Kualo berada pada $0^{\circ} 46$ ' 12,03" LS dan $100^{\circ} 39$ '22,54" BT dengan elevasi $421 \mathrm{~m}$. (Gambar 2). Peta Geologi (Gambar 3) dan Desain Pengukuran di TPAS Ampang Kualo (Gambar 4)

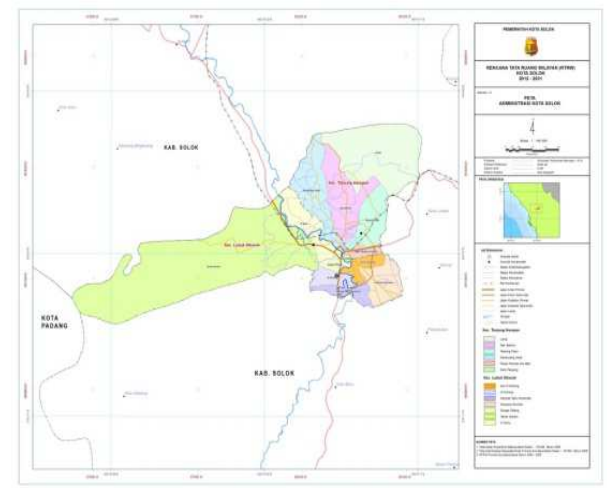

Gambar 2. Peta Lokasi Penelitian

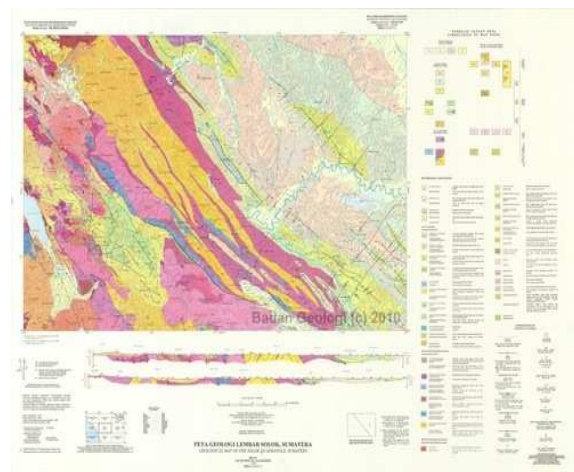

Gambar 3. Peta Geologi Daerah Solok 


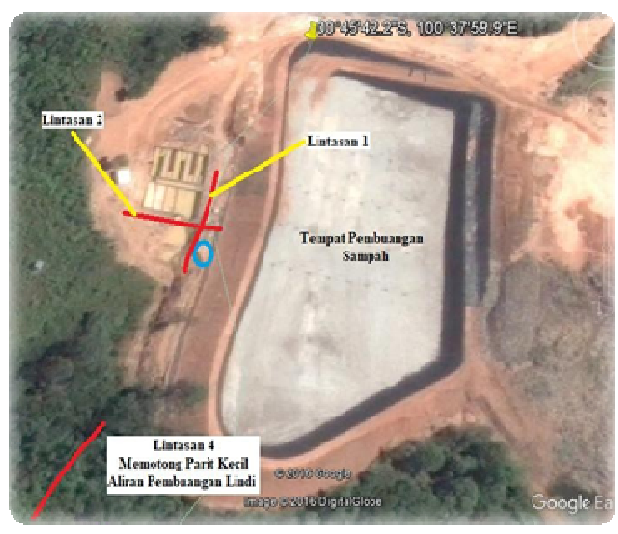

Gambar 4. Desain Pengukuran di TPAS Ampang Kualo

\section{Pengaruh Air Lindi}

Lindi dapat didefinisikan sebagai cairan yang timbul dari hasil dekomposisi biologis sampah yang telah membusuk yang mengalami pelarutan akibat masuknya air eksternal ke dalam timbunan sampah. Air lindi akibat proses degradasi sampah dari TPA merupakan sumber yang mempengaruhi perubahan sifat fisik, kimia maupun biologi.

Air lindi disebabkan oleh terjadinya presipitasi cairan ke TPA, baik dari resapan air hujan maupun kandungan air pada sampah itu sendiri. Lindi bersifat toksik karena adanya zat pengotor dalam timbunan yang mungkin berasal dari buangan limbah industri, debu, lumpur hasil pengolahan limbah, limbah rumah tangga yang berbahaya, atau dari dekomposisi yang normal terjadi pada sampah.

\section{Metode Wanner - Schlumberger \\ Pengukuran dengan konfigurasi schlumberger menggunakan 4} elektroda, masing-masing 2 elektroda arus dan 2 elektroda potensial salah satu metoda geofisika yang dapat digunakan untuk memperkirakan keberadaan dan ketebalan batubara di bawah permukaan adalah metode geolistrik tahanan jenis. Metode geolistrik dapat mendeteksi lapisan batubara pada posisi miring, tegak dan sejajar bidang perlapisan di bawah permukaan. Ilustrasi garis ekuipotensial yang terjadi akibat injeksi arus ditunjukkan pada dua titik arus yang berlawanan di permukaan bumi (Gambar 5).

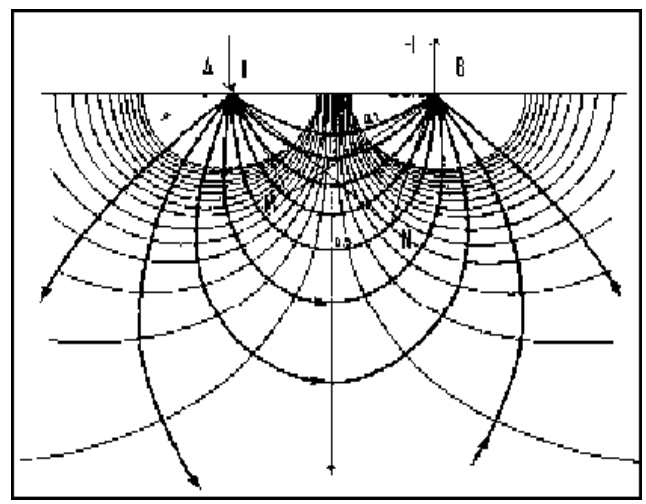

Gambar 5. Pola aliran arus dan bidang ekipotensial antara dua elektroda arus dengan polaritas berlawanan

Beda potensial yang terjadi antara MN yang disebabkan oleh injeksi arus pada $A B$ adalah :

$$
\begin{aligned}
& \Delta V=V_{S I}-V_{Y S} \\
& \Delta V=\frac{I \rho}{2 \pi}\left[\left(\frac{1}{A M}-\frac{1}{B M}\right)-\left(\frac{1}{A N}-\frac{1}{B N}\right)\right] \\
& \rho=2 \pi\left[\left(\frac{1}{A M}-\frac{1}{B M}\right)-\left(\frac{1}{A N}-\frac{1}{B N}\right)\right]^{-1}
\end{aligned}
$$

Sehingga

$$
\rho=k \frac{\Delta V}{I}
$$

Dengan I arus dalam Ampere, AV beda potensial dalam Volt, $\mathbf{p}$ tahanan jenis dalam Ohm meter dan $\mathbf{k}$ faktor geometri elektroda dalam meter, maka:

$$
k=2 \pi\left[\left(\frac{1}{A M}-\frac{1}{B M}\right)-\left(\frac{1}{A N}-\frac{1}{B N}\right)\right]^{-!}
$$

$k$ merupakan faktor koreksi geometri dari konfigurasi elektroda potensial dan elektroda arus. 


\section{METODE PENELITIAN \\ Perlengkapan Data}

Dalam penelitian ini, ada dua macam data yang dibutuhkan yaitu data sekunder dan data primer.

1. Data sekunder antara lain terdiri dari:
a. Peta, yang meliputi peta topografi, geologi peta administrasi wilayah dan lainnya.
b. Laporan atau hasil penelitian terdahulu yang pernah dilakukan di sekitar lokasi penelitian.

2. Data primer yang didapatkan dalam penelitian ini meliputi:
a. Geologi yang meliputi singkapan batuan, keberadaan sesar, kekar, jurus dan arah kemiringan pelapisan dan lain sebagainya.
b. Keadaan morfologi dan ketinggian lokasi studi.
c. Data pengukuran alat resistivity Geolistrik.
d. Data lainnya yang mendukung pelaksaan penelitian ini.

\section{Langkah - Langkah Pengukuran}

Langkah-langkah pengukuran

dengan metode golistrik konfigurasi Wenner dan metode Geolistrik konfigurasi Schlumberger adalah sebagai berikut :

1. Menancapkan elektroda pada permukaan tanah dengan spasi yang telah ditentukan sesuai dengan konfigurasinya.

2. Kabel dibentangkan sebagai penghatar arus dan potensial yang menghubungkan antar elektroda dengan alat resistivitymeter.

3. Setelah keempat elektroda terhubung dengan resistivitymeter, maka pengukuran sudah siap dilakukan.

4. Mencatat arus listrik dan tegangan yang timbul setelah arus diinjeksikan ke dalam tanah.

\section{Hasil Pengukuran}

Dari pengukuran menggunakan MAE X612- EM maka didapatkan nilai yang dibaca yaitu :

1. Kuat arus listrik (I)dalam satuan miliampere $(\mathrm{mA})$.

2. Beda potensial $(V))$ dalam satuan $(\mathrm{mV})$ milivolt.

3. Potensial spontan (PS) dalam satuan $(\mathrm{mV})$ milivolt.

4. Resistivitas semu ( $r$ ) dalam satuan ohm $(\Omega)$ atau miliohm $(\mathrm{m} \Omega)$

5. standard deviasi (st dev)

\section{Pengolahan Data}

Data yang diperoleh dari hasil pengukuran menggunakan $M A E \times 612-$ $E M$ adalah kuat arus listrik (I), beda potensial $(V)$, potensial spontan (PS), resistivitas semu (r), dan standard deviasi (st dev).

Pengambilan data dilakukan dengan tiga lintasan, pengukuran Panjang Lintasan 1 adalah $48 \mathrm{~m}$ dengan spasi elektroda $1 \mathrm{~m}$. Data yang diperoleh pada Lintasan 1 berjumlah 576 data. Panjang Lintasan 2 yaitu $48 \mathrm{~m}$ dengan spasi elektroda 1 $\mathrm{m}$. Data yang diperoleh pada Lintasan 2 yaitu 576 data. Panjang Lintasan 3 yaitu $48 \mathrm{~m}$ dengan spasi elektroda 1 $\mathrm{m}$. Data yang diperoleh pada Lintasan 3 yaitu 576 data.

\section{Interpretasi Hasil Pengolahan Data}

Hasil interpretasi data berupa penampang 2D lapisan bawah permukaan bumi berdasarkan variasi nilai resistivity. Penampang model 2D resistivity menggambarkan respon mineral lapisan bawah permukaan bumi. Variasi nilai resistivity dinyatakan dalam bentuk citra warna yang berbeda-beda dengan kedalaman lapisan tertentu sesuai dengan nilai resistivity.

Analisa mineral yang terdapat di daerah penelitian diestimasi berdasarkan hasil interpretasi nilai resistivity semu. Nilai resistivity yang 
diperoleh dari hasil interpretasi selanjutnya dibandingkan dengan nilai variasi resistivitas material bumi (batuan).

\section{HASIL DAN PEMBAHASAN Deskripsi Data}

Nilai tahanan jenis semu setiap lintasan pengukuran ditunjukkan oleh Tabel 1.

Tabel 1. Nilai Tahanan Jenis Semu Minimum dan Maksimum Tiap Lintasan

\begin{tabular}{|c|c|c|c|c|c|c|}
\hline No & Lintasan & $I(\mathrm{~mA})$ & $V(\mathrm{mV})$ & $\begin{array}{l}P S \\
(\mathrm{mV})\end{array}$ & $r\left(\mathrm{o}^{*} \mathrm{~m}\right)$ & $\mathrm{St}-\mathrm{dev}$ \\
\hline \multirow{2}{*}{1} & Min & 71 & 1 & -480 & 1 & 0 \\
\hline & maks & 593 & 8374 & 787 & 2307 & 0 \\
\hline \multirow{2}{*}{2} & Min & 0 & 0 & -663 & 1 & 0 \\
\hline & maks & 699 & 5832 & 586 & 29722 & 0 \\
\hline \multirow{2}{*}{3} & Min & $\overline{0}$ & $\overline{0}$ & -597 & 1 & $\overline{0}$ \\
\hline & maks & 785 & 6624 & 635 & 35941 & 0 \\
\hline
\end{tabular}

Tabel 1 menunjukkan nilai tahanan jenis semu maksimum dan minimum pada setiap lintasan. Jika Standar deviasinya besar, hal ini berarti makin besar pula variabilitas datanya atau semakin kurang homogen dan tingkat keper-cayaannya rendah. Sebaliknya apabila Standar deviasi kecil, data yang sedang diteliti itu makin dekat kepada sifat homogenitas sehingga tingkat kepercayaannya tinggi. Tingkat kepercayaan hasil pene-litian ini termasuk pada tingkat kepercayaan yang tinggi, hal ini dikarenakan nilai standard deviasi hasil penelitian bernilai kecil.

\section{Proses Inversi}

Proses inversi dengan bantuan software Res2dinv.

\section{Hasil Inversi}

Hasil inversi berbentuk penampang 2D tahanan jenis antara jarak elektroda terhadap kedalaman. Penampang tersebut akan memperlihatkan variasi tahanan jenis sebenarnya.

\section{Interpretasi Data}

Hasil interpretasi data berupa penampang 2D lapisan bawah permukaan bumi berdasarkan variasi nilai resistivity. Penampang model 2D resistivity menggam-barkan respon mineral lapisan bawah permukaan bumi. Variasi nilai resistivity dinyatakan dalam bentuk citra warna yang berbeda-beda dengan kedalaman lapisan tertentu sesuai dengan nilai resistivity. Analisa mineral yang terdapat di daerah penelitian diestimasi berdasarkan hasil interpretasi nilai resistivity semu. Nilai resistivity yang diperoleh dari hasil interpretasi selanjutnya dibandingkan dengan nilai variasi resistivitas material bumi (batuan)

\section{Lintasan 1}

Lintasan 1 terletak pada koordinat 0045'45,67'S-100037'58,24"E dengan ketinggian antara 423,80-424,53 mdpl, memiliki panjang lintasan $48 \mathrm{~m}$ dengan spasi elektroda $1 \mathrm{~m}$. Hasil interpretasi data Lintasan 1 menunjukkan sebaran nilai tahanan jenis medium di bawah permukaan area pengukuran. Nilai tahanan jenis pada lintasan 1 antara $0,005-500 \Omega \mathrm{m}$, dengan kedalaman hingga $7,88 \mathrm{~m}$. Pada jarak 8-10 m lintasan 1 melewati sumur pantau dengan kedalaman muka air 2,6 m. Hasil penampang topografi 2D dari lintasan 1 dapat dilihat pada Gambar 6 berikut ini.

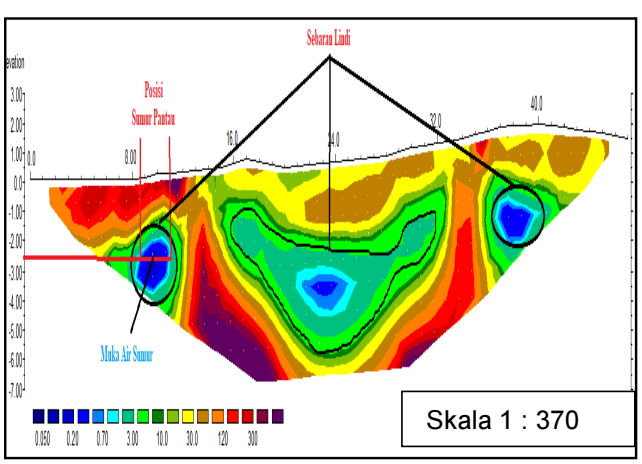

Gambar 6. Penampang Model 2D Topografi Lintasan 1 
Gambar 6 memperlihatkan profil 2D menunjukkan kandungan lapisan bawah permukaan bumi berdasarkan nilai tahanan jenis. Lapisan berwarna biru tua hingga biru muda memiliki nilai tahanan jenis $<3,00$ diestimasi sebagai cairan lindi. Terlihat air lindi yang merembes masuk kedalam tanah pada posisi elektroda 7 sampai elektroda 10 dengan kedalaman 2,30 sampai 4,20 meter, pada elektroda 16 sampai elektroda 18 dengan kedalaman 2,10 sampai 3,70 meter, pada elektroda 19 sampai elektroda 27 dengan kedalaman 3,70 sampai 5,80 meter, pada elektroda 29 sampai elektroda 31 dengan kedalaman 2,49 sampai 3,96 meter, dan pada elektroda 37 hingga 41 dengan kedalaman 220 sampai 425 meter. Selanjutnya daerah yang memiliki haga resistivitas tinggi yang ditandai dengan warna merah sampai ungu diasumsikan sebagai tufa yang merupakan batuan dasar dari daerah penelitian.

\section{Lintasan 2}

Lintasan 2 terletak pada koordinat 0045'45,51's - 100037'57,53"E dengan ketinggian antara 433,55-436,15 mdpl, memiliki panjang lintasan $48 \mathrm{~m}$ dengan spasi elektroda $1 \mathrm{~m}$.

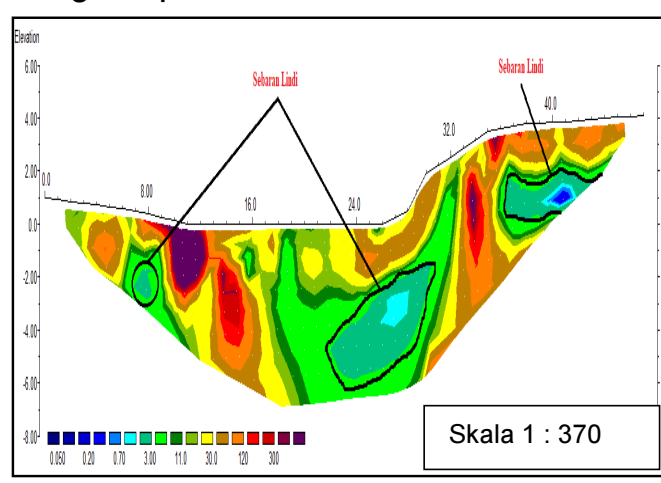

Gambar 7. Penampang Model 2D Topografi Lintasan 2

Hasil interpretasi data Lintasan 2 menunjukkan sebaran nilai tahanan jenis medium di bawah permukaan area pengukuran. Nilai tahanan jenis pada lintasan 2 antara 0,005-500 $\Omega \mathrm{m}$, dengan kedalaman hingga 7,38 m.

Gambar 7 memperlihatkan profil 2D menunjukkan kandungan lapisan bawah permukaan bumi berdasarkan nilai tahanan jenis. Lapisan berwarna biru tua hingga biru muda memiliki nilai tahanan jenis $<3,00$ diestimasi sebagai cairan lindi. Terlihat air lindi yang merembes masuk kedalam tanah pada posisi elektroda 7 sampai elektroda 9 dengan kedalaman 1,70 sampai 2,90 meter, pada elektroda 21 sampai elektroda 30 dengan kedalaman 2,69 sampai 6,35 meter, dan pada elektroda 36 sampai elektroda 44 dengan kedalaman 1,50 sampai 3,80 meter. Selanjutnya daerah yang memiliki haga resistivitas tinggi yang ditandai dengan warna merah sampai ungu diasumsikan sebagai tufa yang merupakan batuan dasar dari daerah penelitian.

\section{Lintasan 3}

Lintasan 3 terletak pada koordinat 0045'48,22'S - 100037'54,44'E dengan ketinggian antara 420,00-421,169 $\mathrm{mdpl}$, memiliki panjang lintasan $48 \mathrm{~m}$ dengan spasi elektroda $1 \mathrm{~m}$. Nilai tahanan jenis pada lintasan 2 antara 0,005-500 $\Omega \mathrm{m}$, dengan kedalaman hingga $7,38 \mathrm{~m}$.



Gambar 8 memperlihatkan profil 2D menunjukkan kandungan lapisan bawah permukaan bumi berdasarkan 
nilai tahanan jenis. Lapisan berwarna biru tua hingga biru muda memiliki nilai tahanan jenis < 3,00 diestimasi sebagai cairan lindi. Terlihat air lindi yang merembes masuk kedalam tanah pada posisi elektroda 1 sampai elektroda 4 dengan kedalaman 1 sampai 2 meter, pada elektroda 4 sampai elektroda 5 dengan kedalaman 0,25 sampai 1 meter, pada elektroda 7 sampai elektroda 8 dengan kedalaman 1,35 sampai 2,69 meter, pada elektroda 10 sampai elektroda 12 dengan kedalaman 1,10 sampai 2,50 meter, pada elektroda 19 sampai elektroda 20 dengan kedalaman 2,60 sampai 3 meter, dan pada elektroda 28 sampai elektroda 31 dengan kedalaman 6,25 sampai 7,38 meter. Selanjutnya daerah yang memiliki haga resistivitas tinggi yang ditandai dengan warna merah sampai ungu diasumsikan sebagai tufa yang merupakan batuan dasar dari daerah penelitian.

Pengolahan data menggunakan metode analisis inversi dengan bantuan software Res2dinv. Hasil penelitian menunjukkan bahwa pada daerah penelitian di TPA Ampang Kualo lapisan bawah permukaan tersusun oleh batuan dan mineral, yaitu Groundwater, Sandstones, Clay, dan batu Andesite. Langkah selanjutnya yang dilakukan adalah mengestimasi jenis batuan penyusun daerah penilaian berdasarkan nilai tahanan jenis dan keadaan geologi.

Lintasan satu dan dua memiliki ketinggian yang lebih tinggi dibandingkan Lintasan tiga. Lintasan satu dan dua berada \pm 30 meter dengan tempat penampungan sampah dan bersebelahan juga dengan kolam penampungan lindi \pm 5 meter, lalu lintasan tiga berada di area pemukiman penduduk memo-tong parit kecil tempat aliran pembuangan lindi.
Groundwater pada lintasan satu, dua dan tiga ini diduga telah tercemar oleh lindi. Pada lintasan satu pencemaran yang terjadi diduga berasal dari rembesan lindi karena lintasan ini berada di sekitar tumpukan sampah. Dengan demikian lindi akan lebih mudah telinfiltrasi ke Groundwater. Keberadaan Groundwater pada lintasan ini seperti terlihat pada Gambar 9 berikut ini.

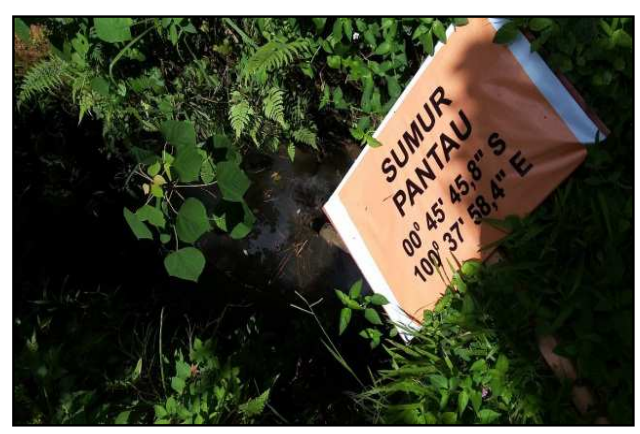

Gambar 9. Sumur pantau

Resistivitas fresh groundwater adalah antara 10-100 $\Omega \mathrm{m}$, groundwater yang tercemar memiliki resistivitas kecil dari $10,00 \Omega m$ dikarenakan oleh lindi memiliki konduktivitas yang tinggi, akibatnya resistivitas lindi kecil. Lindi pada area TPA memiliki konsentrasi yang tinggi, yang akan bersesuaian dengan nilai konduktivitas yang sangat tinggi dan nilai resistivitas yang sangat rendah. Sehingga apabila lindi bercampur dengan air tanah maka resistivitas akan menurun atau semakin kecil. Berikut titik-titik sebaran cairan lindi dari ketiga lintasan seperti terlihat pada Gambar 10 berikut ini 


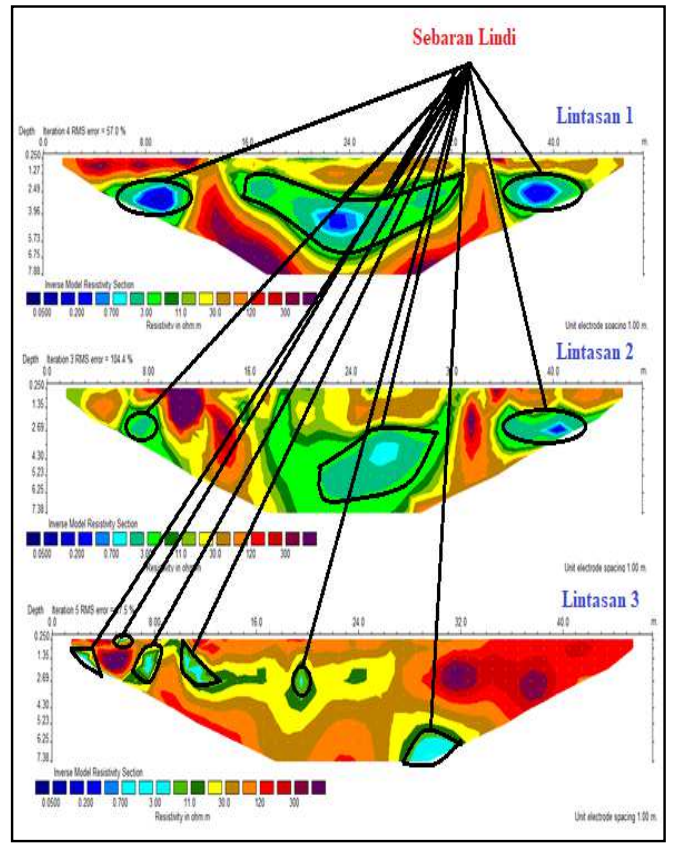

Gambar 10. Sebaran cairan lindi masing-masing lintasan

Data geolistrik 2D dapat ditampilkan dalam bentuk penampang 3D dengan bantuan software Voxler. Data geolistrik 2D yang dapat diubah menjadi tampilan 3D ini merupakan gabungan dari beberapa lintasan pengukuran dengan syarat lintasan yang digabung harus sejajar. Penampang 3D ini diharapkan dapat menampilkan lokasi penelitian secara keseluruhan dengan bentuk 3D seperti terlihat pada Gambar 11 dan 12 berikut ini.

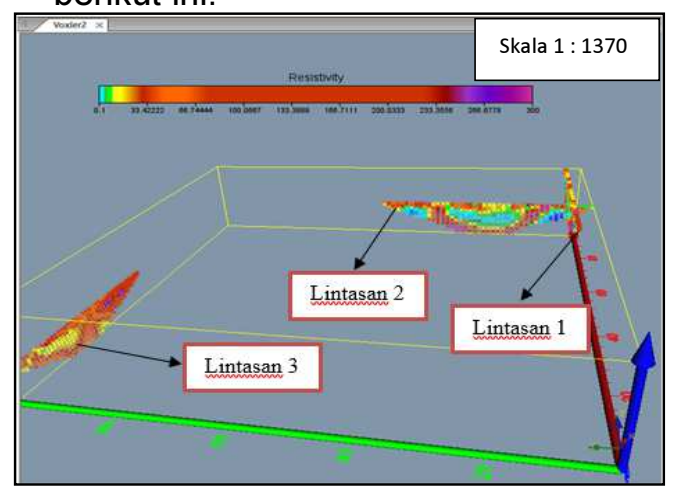

Gambar 12. Gambaran 3D bawah permukaan ke tiga lintasan

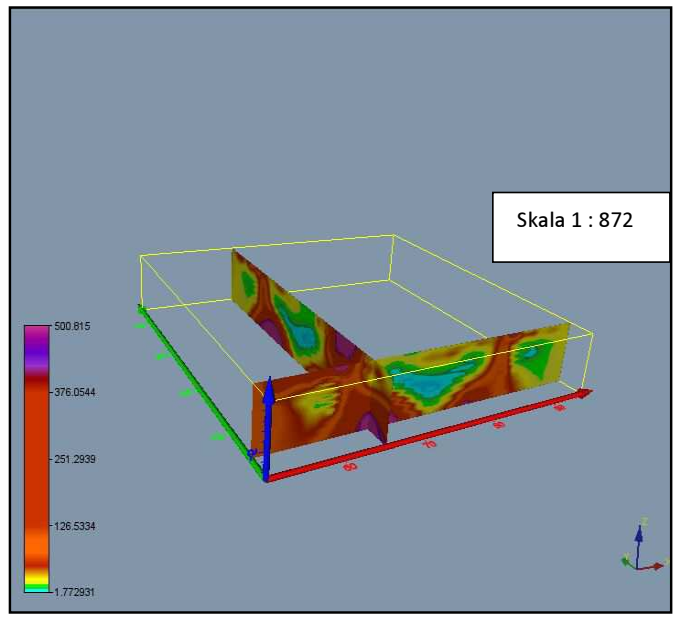

Gambar 13. Gambaran 3D bawah permukaan Lintasan satu dan dua

\section{KESIMPULAN}

1. Lapisan penyusun bawah permukaan bumi TPA Ampang Kualo Kota Solok, yaitu groundwater, sandstones, clay, dan Andesite.

2. Sebaran air lindi dominan ke arah selatan hingga barat daya mengikuti aliran parit kecil pembuangan air lindi yang mengarah ke perumahan Green Hills Arya, dikarenakan daerah topografi pemukiman penduduk lebih rendah dari TPA Ampang Kualo.

3. Pencemaran air tanah terjadi pada setiap lintasan pengukuran penelitian. Pencemaran air tanah terjadi karena nilai tahanan jenis air tanah setiap lintasan $<10,00$ $\Omega \mathrm{m}$ dan terdapatnya akumulasi cairan lindi pada lapisan groundwater di lintasan pengukuran. Pada lintasan 1 pencemaran air tanah ditemukan pada kedalaman 2,10-5,80 meter, pada lintasan 2 terjadi pada kedalaman 1,50-6,35 meter dan pada lintasan 3 terjadi pada kedalaman 0,25-7,38 meter. 
DAFTAR PUSTAKA

[1] Anton Kuswoyo, Ali Masduqi, Pemetaaan Air Tanah Sebagai Sumber Air Bersih di Daerah Pesisir Pantai Batakan Kabupaten Tanah Laut, Jurnal Teknologi \& Industri Vol 3 No.1 Juni 2014

[2] Dahlin, Torleif. (1993), On the automation of $2 D$ resistivity surveying for engineering snd environmental applications, Depertemen of engineering geology, Lund Institute of Technology, Lund University

[3] Gusfan Halik, Jojok Widodo S, Pendugaan Potensi Air Tanah dengan Metode Geolistrik Konfigurasi Schlumberger di Kampus Tegal Boto Universitas Jember, Media Teknik/ Juli 2008/ 109

[4] I K Putra,IM Sudiana, I.P.G. Ardana, Identifikasi Arah Rembesan dan Letak Akumulasi Lindi dengan Metode Geolistrik Resistivitas Konfigurasi WennerSchlumberger di TPA Temesi Kabupaten Gianyar, ECOTOPHIC, Volume 7 Nomor 1 tahun 2012

[5] Juandi M. Analisa Pencemaran Air Tanah BerdasarkanMetode

Geolistrik Studi Kasus Tempat Pembuangan Akhir Sampah Muara Fajar Kecamatan Rumbai. IImu Lingkungan Jurnal of Eviromental Science, ISSN 1978-5283

[6] Lean wijaya, Identifikasi Pencemaran Air Tanah dengan Metode Geolistrik di Wilayah Ngringo Jaten
Karanganyar, Universitas Udayana 2012

[7] Lufti Gita Iriani, Analisis Kualitas Air Tanah Bebas di Sekitar TPA Banyuroto Desa Banyuroto Kecamatan Nanggulan Kabupaten Kulon Progo Yogyakarta. Fakultas Geografi UMS 2014

[8] Ngadimin, Gunawan Handayani, Aplikasi Metode Geolistrik untuk Alat Monitoring Rembesan Limbah. JSM. Vol 6 No 1 hal 43 - 53, April 2001

[9] Reynolds, J.M. (1997), An introduction to applied and environmental geophysic, John Welly \& Sons. New York.

[10] Supriadi, Khumaedi, Panca R.N, Pola Sebaran Limbah TPA Stud Kasus di Jatibarang Semarang, J.Manusia dan Lingkungan. Vol. 20 No 1. Maret 2013 4956

[11] Telford, dkk. (1990), Applied geophysic second edition, Cambridge University Press. 